\title{
Identidade judaica: formação, manutenção e possível modificação à luz da Psicologia Social
}

\author{
Solange Epelboim 1
}

\begin{abstract}
Resumo
A pesquisa examinou a configuração de ser judeu, a partir da Psicologia Social. Tal proposta reuniu considerações teóricas e observações empíricas. Quanto àquelas, foram elaborados comentários sobre identidades psicossociais, judaísmo, entre outras questões. Quanto aos aspectos empíricos, foi desenvolvido estudo de campo, com aplicação de questionário com perguntas abertas, cujas respostas foram examinadas com base na análise de conteúdo. Participaram da pesquisa 80 israelitas, sendo 40 ashkenazim e 40 sefaradim, cujas idades variaram entre 15 e 81 anos. Estes grupos foram compostos, respectivamente, por 20 homens e mulheres, dos quais 10 apresentavam nível médio e 10 superior de escolaridade. Resultados indicaram presença comum de categorias entre ashkenaz̧im e sefaradim. Concluiu-se que ser judeu compreendia, sobretudo, aspectos religiosos e culturais. Quanto aos processos de formação, manutenção e modificação, houve predominância de fatores culturais e educacionais; culturais, religiosos, emocionais e sociais; e socioculturais.

Palavras-Chave: Psicologia social; Identidade; Judaísmo.
\end{abstract}

\section{Jewish identity: formation, maintenance and possible modification under Social Psychology}

\begin{abstract}
The research examined the configuration of being Jewish, under Social Psychology. This research made theoretical considerations and empirical observation. As regards the theoretical considerations, commentaries were made concerning psychosocial identity and Judaism. The empirical observations were based on a field study, with the application of a questionnaire, whose answers were examined through analyses of the content. The participants were 80 Israelis, being 40 ashkenazim and 40 sefaradim, with ages ranged from 15 to 81 years old. These groups were composed, respectively, by 20 men and women, each one with 10 participants with medium level of education and ten with high level. Results showed the common presence of categories. Being Jewish included, above all, religious and cultural aspects. As regards the processes of formation, maintenance and modification the predominance of cultural and educational; cultural, religious, emotional and social; and social cultural aspects were observed.

Keywords: Social psychology; Identity; Judaism.
\end{abstract}

\section{Introdução}

No que tange à compreensão do termo identidade, Epelboim (1997) adotou definições que caracterizavam o referido verbete como vinculado à qualidade de idêntico, isto é, como capaz de reunir um conjunto de fatores próprios e exclusivos a cada pessoa, fatores que possibilitariam que o sujeito fosse reconhecido como ele mesmo (Hollanda, 1967); como compreendendo aspectos de ordem objetiva, subjetiva, individual e social (Erikson, 1968); como implicando na percepção da constante articulação entre permanência e mudança de princípios e propósitos apresentados pela pessoa (Drever, 1965); como envolvendo características centrais de um indivíduo, as quais guardariam compromisso com uma concepção de homem em constante e dinâmica construção (Rorty \& Wong, 1990); como relacionado ao desenvolvimento psicossocial do sujeito através da passagem por fases (Erikson, 1976, 1987), entre outras considerações. Entretanto, optou-se por se conceder destaque ao entendimento do conceito de identidade com base na noção psicossociológica de crença.

De acordo com Krüger (1995a), o conceito de crença pode ser definido enquanto proposição que afirma ou não a existência de relações entre objetos concretos ou abstratos, ou entre objetos e propriedades a eles atribuídas, sendo admitidas por pessoas. Krüger (1995b) compreendeu identidade como a consciência que todo indivíduo tem de si mesmo, de sua origem, filiação, relações que estabelece com os demais, atributos físicos e psicológicos, enfim, fatores capazes de o diferenciarem de outros indivíduos. Tal nível de conscientização propicia o surgimento de crenças neste homem sobre sua unidade, a qual expressa a

\footnotetext{
1 Endereço para correspondência

Av. Presidente Vargas, 590/1812 - Centro - Rio de Janeiro-RJ - 20071-000

E-mail: epelboim@ig.com.br

Agradeço ao professor dr. Helmuth Krüger, orientador que, com excelência, dedicação e seriedade, contribuiu para a elaboração da dissertação.

A dissertação, ora apresentada em forma de artigo, recebeu apoio financeiro do CNPq.
} 
organização e coerência deste quanto à sua personalidade e conduta. Estas crenças se caracterizam por constituir a identidade e por serem obtidas a partir das inúmeras experiências vividas por cada pessoa ao longo de seu desenvolvimento, cabendo ressaltar aquelas que se dão durante o processo de socialização.

Krüger (1995c) ainda destacou quatro aspectos envolvidos na configuração do conceito em questão. Deste modo, afirmou que a identidade pode ser apresentada como tendo sua origem na apercepção de características pessoais, ou seja, na apercepção que uma pessoa tem de seus atributos físicos e psicológicos, a qual envolve considerável tomada de consciência e permite que este indivíduo alcance a crença de que seja diferente de outros em alguns aspectos. Uma segunda característica apontou para a possibilidade que qualquer sujeito tem de distinguir, em sua auto-representação simbólica, a existência de diversas dimensões, isto é, das variadas formas de identidade por ele apresentadas ao se inserir em grupos, coletividades e processos sociais. Uma terceira característica indicou que a identidade se constitui com base em crenças autodescritivas e auto-avaliativas, as quais lhe conferem um caráter dinâmico que permite mudanças. Por fim, o sistema de crenças avaliativas e autodescritivas contribui de modo significativo para o desenvolvimento da personalidade e da conduta dos indivíduos.

Ainda de acordo com Krüger (1986), a análise da formação do ser social parece implicar na articulação entre os processos de construção, sustentação e possível modificação de identidade e o processo de socialização, pois mediante a socialização se opera a progressiva transformação de um recém-nascido, cujas condutas são inicialmente determinadas por reflexos e respostas não condicionadas, em um ser social. Faz-se necessário comentar que tal passagem revela a mútua interferência entre o sujeito e o contexto onde o mesmo se apresenta. Deste modo, pode-se caracterizar resumidamente o processo de socialização como dinâmico, universal e contínuo, isto é, onde as pessoas influenciam umas as outras e, conseqüentemente, são influenciadas a todo momento, movimento que ocorre em toda e qualquer sociedade, e que acompanha o homem ao longo de sua vida.

De acordo com Pereira e Jesuíno (1985), poder-se-ia conceituar a socialização em termos de aprendizagem de papéis sociais, os quais seriam definidos como o comportamento que é esperado, por outras pessoas, de um indivíduo que ocupa uma determinada posição social. Assim, a socialização compreenderia a aprendizagem, por parte da pessoa em questão, em desempenhar diversos papéis sociais, considerando as expectativas que os outros apresentam em relação à história de vida desta. Embora o conceito de papel social possa ser deste modo exposto, cabe ressaltar que o mesmo caracteriza-se por ser bastante discutido e ainda não precisamente definido.

Neste sentido Dahrendorf (1969), ao apresentar o ponto de intersecção entre o indivíduo e a sociedade, situou o "homo sociologicus" e o definiu como sendo o homem portador de papéis sociais preformados, isto é, a pessoa vestindo diferentes "máscaras" no decorrer de sua vida. Diante de cada posição social que a mesma viesse a ocupar, a sociedade estabeleceria atributos e modos de comportamento. $\mathrm{O}$ indivíduo, ao entrar em contato com tais exigências sociais, precisaria tomar uma decisão, quer as aceitando e cumprindo (o que poderia implicar em variados graus de renúncia de sua individualidade), quer resistindo às mesmas (o que poderia contribuir para a manutenção de sua independência, porém, implicando sanções por parte da sociedade). Entretanto, este "homo sociologicus" não representaria o homem em seu aspecto global, uma vez que existiria uma área onde cada indivíduo seria livre, sendo capaz de estruturar seus próprios papéis e delinear suas formas de comportamento para o desempenho destes.

De acordo com Augoustinos e Walker (1995), a reflexão sobre o delineamento da identidade acompanha o homem ao longo de sua história. Os autores salientaram que, na tentativa de responder a tal pergunta, pesquisadores em Psicologia Social estabeleceram uma divisão entre identidade pessoal e identidade social. Enquanto aquela se dirigia a características individuais, esta apontava para a condição do sujeito se perceber enquanto membro de um grupo, de modo a também incluir em sua configuração a valorização e significância emocional deste pertencimento. Cabe esclarecer que a identidade social seria associada a grupos dos quais o indivíduo participasse, assim como a conjuntos de referência, onde não houvesse a inclusão do mesmo.

Entretanto, segundo Augoustinos e Walker (1995), a divisão entre identidade pessoal e social era inadequada, pois não haveria como se pensar em uma identidade pessoal afastada de uma identidade social. Concorda-se com esta posição, fato que se torna explícito ao analisarmos a construção do ser social tomando por base o conceito de identidade psicossocial, isto é, uma configuração que contemple fatores privados, públicos e, sobretudo, relativos à vinculação entre o particular e o coletivo.

Por fim, salientaram que o objetivo do ser humano consistiria em desenvolver identidade social e auto-estima positivas. Lembraram que o desenvolvimento de identidade social positiva iria requerer cuidado, a fim de que este processo não implicasse em coesão grupal mediante perda significativa de autonomia individual, desrespeito ante grupos sociais distintos do conjunto em questão, e conflitos e hostilidade intergrupos. Tais observações parecem vir ao encontro de discussões acerca de aspectos individuais e coletivos na constituição de 
identidades psicossociais (Brewer \& Gardner, 1996; Deaux, Reid, Mizrahi \& Ethier, 1995; Oyserman, 1993; Reid \& Deaux, 1996, entre outros autores).

\section{Identidade Judaica}

Os hebreus, israelitas ou judeus podem ser apresentados como aqueles que compõem o povo de Israel, povo este escolhido, dentre outros povos, para receber a Lei divina. De acordo com o Judaísmo, a Lei divina é transmitida através da Torá, isto é, através de livros que foram escritos por Moisés quando Deus revelou, ao mesmo, sua Lei. A Torá reúne histórias sobre a criação do Universo, da Humanidade e do povo hebreu, destacando, com base em recursos descritivos, normativos e avaliativos, toda a legislação civil e religiosa que deve perpassar a existência dos israelitas.

Quanto à caracterização do povo de Israel enquanto povo eleito por Deus, é necessário que se compreenda tal expressão como referente, unicamente, ao fato de que Deus escolheu os judeus para que recebessem sua Lei, cumprissem os mandamentos contidos na mesma e a estudassem, a fim de poderem segui-la de forma consciente. Deste modo, esta escolha não deve, em hipótese alguma, ser interpretada por um prisma etnocêntrico, ou seja, significando a superioridade de um povo em detrimento de quaisquer outros, quer esta superioridade seja defendida por critérios religiosos, étnicos, sociais, econômicos, políticos ou morais. Segundo Lillenthal (1997), a eleição deve ser compreendida como marcada pela condição de obediência, dever e serviço a Deus. Tal condição revela que o povo de Israel foi escolhido apenas como instrumento para garantir o cumprimento de um propósito divino maior - a defesa do monoteísmo. Lillenthal (1997) adverte ainda que a relação entre Deus e o povo judeu, embora particular, não é exclusiva, mas extensiva a toda a humanidade.

Tomando por base as considerações apresentadas, observa-se que os termos hebreu, israelita e judeu são entendidos no presente trabalho enquanto sinônimos. Esta condição de equivalência se justifica, pois os três termos se referem ao mesmo grupo de pessoas. A fim de proporcionar maior esclarecimento conceitual, cabe mencionar que o termo hebreu é relacionado por Corrêa Neto (1987) a Héver, um dos antepassados de Abraão; à palavra ever, que em hebraico significa lado, margem, apontando o patriarca Abraão como aquele que veio da outra margem, de além Jordão e Eufrates, de origem mesopotâmia; à palavra ivri, que em hebraico significa travessia, o que mais uma vez assinala a origem de Abraão; e a Habirus ou Hapirus, nomes aplicados aos nômades pastores e guerreiros, grupos aos quais os patriarcas pertenceram ou se assemelhavam. Já o termo israelita é vinculado aos descendentes de Jacob, patriarca que passa a ser chamado posteriormente por Israel. O termo judeu passa a ser empregado quando há a criação das doze tribos, as quais dão origem ao Reino de Israel e ao Reino de Judá. Após o desaparecimento das dez tribos do norte, as quais compunham o Reino de Israel, o termo judeu passa a ser aplicado a todos os hebreus. Corrêa Neto (1987) comenta que a designação mosaísta também pode ser relacionada ao povo judeu, uma vez que o mesmo obedece às Leis oferecidas por Deus a Moisés.

Os israelitas se mostram presentes em diversos países do mundo, condição esta estimulada pelas inúmeras perseguições por eles sofridas. Além desta explicação, vertentes do pensamento judaico vinculam tal dispersão a outras razões, ou seja, quer ao nãocumprimento dos mandamentos divinos, quer à possibilidade de transmissão do Judaísmo. A despeito destas discussões em torno das razões que levaram os israelitas a viver em diversos locais do mundo, acreditase que a presença de israelitas em diferentes lugares não comprometa o caráter de unidade, solidariedade e organização exposto por tal grupo. Entretanto, embora o povo de Israel possa ser caracterizado por sua coesão, é importante destacar que tal união não se refere à homogeneidade do conjunto em questão. Isto porque a comunidade judaica é constituída por subgrupos distintos, os quais se diferenciam de acordo com a origem histórica e geográfica que apresentam.

Ao analisar quem são os israelitas, Asheri (1995) expõe que os mesmos podem ser reunidos em três grupos - os ashkenazim, os sefaradim e os "outros". Quanto à primeira categoria, poder-se-iam identificar os ashkenarim como os judeus europeus, cujas origens geográficas e/ou históricas não são espanhola ou portuguesa, e seus descendentes. Percebe-se, ainda, que aspectos culturais influenciam nesta caracterização, pois este grupo se diferencia do sefaradita através de particularidades existentes em suas cerimônias religiosas, prática de rituais, culinária, língua falada em domínios privados, entre outros fatores. No que tange ao idioma utilizado, os ashkenazim podem ser apresentados como aqueles que falam, ou falavam, o idiche. Embora estas pessoas se comunicassem entre si principalmente através do idiche, as mesmas também conheciam e falavam a língua do país onde viviam.

Com relação à segunda categoria anteriormente citada, poder-se-iam identificar os sefaradim como os judeus europeus de origem espanhola e/ou portuguesa, seus descendentes e, ainda, aqueles que, embora não possuam tais origens, tenham adotado o rito espanhol em suas preces e práticas religiosas. Deste modo, percebe-se que o grupo sefaradita também apresenta características próprias, as quais o distinguem dos demais conjuntos existentes. Dentre estas particularidades, observa-se que os sefaradim se comunicam em 
domínios privados através, principalmente, da língua espanhola ou do ladino, isto é, um dialeto que muitos lingüistas definem como judeo-espanhol.

Asheri (1995) afirma que a categoria "outros" compreenderia as pessoas que não pertencessem quer a comunidade ashkenazita, quer sefaradita. Deste modo, ressalta que os componentes deste grupo seriam os israelitas que viviam nos continentes africano e asiático e seus descendentes.

Epelboim (1997), a fim de examinar os processos de formação, manutenção e possível modificação da identidade judaica, desenvolveu breves comentários acerca da história do povo israelita; da presença de judeus no Brasil; de crenças e valores básicos no judaísmo, momento em que foi conferida ênfase aos Dez Mandamentos; e das vertentes ortodoxa, conservadora e reformista do Judaísmo, e suas relações com culturas não-judaicas. A pesquisa, ora comentada, visou ao alcance de determinadas metas, as quais podem ser classificadas em objetivos teóricos (identificar as principais dimensões da identidade judaica, pela análise de dados obtidos ao longo de uma proposta empírica) e pragmáticos (proporcionar informações a israelitas; contribuir para a articulação entre a configuração da identidade judaica e o exercício da razão e da moralidade, e não com ações de cunho etnocêntrico ou que concedessem prioridade à desmedida aculturação; e fornecer informações a pessoas não-israelitas, com o intuito de minimizar e evitar a presença de preconceitos, ações discriminatórias e uso socialmente inadequado de estereótipos).

\section{Método}

\section{Participantes}

Participaram da pesquisa 80 pessoas israelitas residentes na cidade do Rio de Janeiro. Este número foi adotado uma vez que, entre os itens reunidos na parte relativa aos dados pessoais, optou-se por conceder destaque aos fatores referentes à origem ashkenazi ou sefaradi, ao gênero e ao nível de escolaridade. O cruzamento destes itens implicou na emergência de oito grupos (Tabela 1), os quais contaram com a participação de 10 pessoas. Cabe mencionar que os outros itens foram considerados como suporte capaz de contribuir para melhor compreensão das respostas fornecidas pelos participantes.

Tabela 1 - Participantes

\begin{tabular}{|c|c|c|c|c|c|}
\hline \multirow{2}{*}{ origem } & \multirow{2}{*}{ gênero } & \multirow{2}{*}{ escolaridade } & \multirow{2}{*}{ grupos } & \multicolumn{2}{|c|}{ somatórios } \\
\hline & & & & parcial & total \\
\hline \multirow{2}{*}{ ashzenazita } & masculino & $\begin{array}{c}\text { médio } \\
\text { superior }\end{array}$ & $\begin{array}{l}\mathrm{a} \\
\mathrm{b}\end{array}$ & \multirow{2}{*}{$\mathrm{s} 1=\mathrm{a}+\mathrm{b}+\mathrm{c}+\mathrm{d}$} & \multirow{4}{*}{$\mathrm{st}=\mathrm{s} 1+\mathrm{s} 2$} \\
\hline & feminino & $\begin{array}{l}\text { médio } \\
\text { superior }\end{array}$ & $\begin{array}{l}\mathrm{c} \\
\mathrm{d}\end{array}$ & & \\
\hline \multirow{2}{*}{ sefaradita } & masculino & $\begin{array}{c}\text { médio } \\
\text { superior }\end{array}$ & $\begin{array}{l}\mathrm{e} \\
\mathrm{f}\end{array}$ & \multirow{2}{*}{$\mathrm{s} 2=\mathrm{e}+\mathrm{f}+\mathrm{g}+\mathrm{h}$} & \\
\hline & feminino & $\begin{array}{l}\text { médio } \\
\text { superior }\end{array}$ & $\begin{array}{l}\mathrm{g} \\
\mathrm{h}\end{array}$ & & \\
\hline
\end{tabular}

Quanto à idade, colaboraram com a presente investigação pessoas de 15 a 81 anos. Com relação ao estado civil, 20 participantes eram solteiros; 49 eram casados com pessoa israelita; dois eram casados com pessoa não-israelita; seis eram separados de pessoa israelita; um era separado de pessoa não-israelita e dois eram viúvos de pessoa israelita. Com relação à filiação, todos os colaboradores eram filhos de pais judeus. Cinqüenta e seis sujeitos informaram ter filhos, um mencionou que sua esposa estava grávida e vinte e três afirmaram não ter filhos. Quanto à crença e prática religiosa, 59 pessoas se apresentaram como não-ortodoxas; 15 como ortodoxas; duas como tradicionais; uma como religiosa, mas não extremista; uma como religiosa liberal; uma como praticante e uma como de uma categoria entre a forma ortodoxa e a não-ortodoxa. No que se refere às profissões exercidas pelos participantes, é oportuno apenas destacar que 25 sujeitos desenvolviam atividades relacionadas à comunidade judaica carioca e um afirmou tê-las realizado.

\section{Instrumento de Pesquisa}

A pesquisa realizada, ao pretender examinar a configuração da identidade judaica, compreendeu a aplicação de um questionário, o qual apresentou três partes, consistindo a primeira em instruções destinadas aos participantes da pesquisa. A segunda parte consistiu em dados pessoais referentes a idade, gênero, nível de escolaridade, profissão, estado civil, paternidade ou maternidade, filiação, a origem ashkenaz̧i ou sefaradi e a concepção ortodoxa ou não-ortodoxa do judaísmo. Por fim, a terceira parte consistiu em um questionário de nove perguntas abertas, que ofereceu ainda um espaço para que os participantes, caso desejassem, pudessem 
expor seus comentários, críticas e/ou sugestões quanto à pesquisa.

No que tange aos assuntos analisados por cada questão, cabe esclarecer que a pergunta número 1 se referiu à configuração da identidade judaica, enquanto as perguntas 2, 4 e 6 abordaram, respectivamente, os processos de formação, manutenção e modificação da identidade em questão. Imaginou-se que os participantes da pesquisa pudessem vir a responder a estas últimas perguntas recorrendo ao plano do ideal, isto é, destacando fatores que estivessem distantes de suas ações enquanto israelitas. No intuito de incentivar os participantes a refletirem sobre fatores próximos à sua realidade, formularam-se as perguntas 3 e 5 . A questão 7, por sua vez, só era respondida por aqueles que concordassem com a pergunta 6 , e se referia aos fatores que contribuíram para a ocorrência de modificações na identidade judaica. A pergunta 8 pretendeu analisar os aspectos étnicos da identidade considerada. Por fim, a questão 9 buscou investigar se a identidade judaica compreendia, em sua configuração, aspectos políticos.

\section{Procedimento}

A pesquisa consistiu na realização de um estudo de campo, durante o período compreendido entre os anos de 1996 e 1997. Em razão do grande número de israelitas residentes no Brasil, fez-se necessário escolher um determinado conjunto. Infelizmente, não foi possível destacar o número exato de pessoas judias residentes no Brasil e na cidade do Rio de Janeiro, uma vez que tal número parecia só existir de modo aproximado.

Com base em informações obtidas junto à Federação Israelita do Rio de Janeiro (FIERJ), pôde-se estimar a presença de 200 mil judeus no Brasil e de 40 a 50 mil judeus na cidade do Rio de Janeiro. Enquanto a primeira estimativa pôde ser obtida mediante informações fornecidas por diferentes instituições representativas da colônia judaica existente no Brasil, a segunda baseou-se no número de famílias israelitas cariocas cadastradas para o recebimento da mala direta da FIERJ. De acordo com estes dados, havia 12 mil famílias cadastradas. Ao se considerar cada família sendo composta por quatro membros, alcançou-se o total de 48 mil pessoas judias residentes no Estado do Rio de Janeiro. Porém, a maioria desses indivíduos vivia na cidade do Rio de Janeiro (aproximadamente 90\%), o que talvez explique a apresentação desses números como referentes ao Estado e à cidade em questão.

Cabe esclarecer que as pessoas foram convidadas a participar da pesquisa pela própria autora e, também, por indivíduos que se propuseram a ajudar na distribuição dos questionários. A autora contou com a participação de pessoas que desempenhavam, ou não, funções relacionadas às esferas religiosa, educacional, política e sociocomunitária do grupo investigado. Deste modo, entre os participantes encontram-se rabinos, profissionais de escolas israelitas, representantes da FIERJ, representantes políticos da cidade do Rio de Janeiro, membros de organizações com compromisso sionista e sociocomunitário, membros de movimentos juvenis, entre outras pessoas. Quanto à aplicação do instrumento de pesquisa, faz-se necessário mencionar que o questionário era entregue ao participante e este, então, informava se preferia respondê-lo e entregá-lo imediatamente, ou se preferia responder e deixar o mesmo ser recolhido posteriormente.

\section{Análise dos Dados}

Os dados obtidos valendo-se das respostas dos participantes foram tratados mediante análise de conteúdo, método que compreende exame qualitativo e quantitativo. Quanto àquele, inicialmente foram destacadas marcas ou unidades que se apresentaram como significativas nas respostas fornecidas. Em seguida, essas marcas foram analisadas e reunidas em categorias. Observou-se, então, a freqüência com que tais categorias apareciam. Após a mensuração da freqüência, buscou-se compreender o que os números pareciam revelar.

Cabe salientar que, considerando-se os fatores referentes à origem ashkenazi ou sefaradi, ao gênero masculino ou feminino, e ao nível médio ou superior de escolaridade, foram inicialmente desenvolvidos comentários acerca de cada um dos respectivos aspectos e, em um segundo momento, foram estabelecidas comparações entre os referidos fatores. Entretanto, faz-se necessário informar que a pesquisa não teve a pretensão de investigar todas as comparações possíveis, visando apenas analisar aquelas que se revelaram mais significativas.

\section{Resultados}

Tendo por base as respostas fornecidas à definição de ser israelita (Tabela 2), observou-se que foi conferido destaque, sobretudo, a aspectos religiosos (categoria que reuniu, entre outras marcas, a crença em Deus, a observância dos mandamentos divinos e a freqüência à sinagoga), emocionais (os quais revelavam o orgulho de ser judeu, o se sentir judeu, entre outras condições) e étnicos (categoria que englobou, entre outros itens, pertencer a um grupo particular; ser membro de conjunto com características religiosas, socioculturais e históricas específicas). Cabe comentar que tal destaque foi conferido tanto por ashkenazim, como por sefaradim. Com relação àqueles, foi também conferida importância a aspectos culturais (os quais reuniam, entre outros fatores, a existência e manutenção de tradições e costumes específicos), enquanto sefaradim indicaram o papel desempenhado por aspectos relativos à descendência (nascer de ventre judeu). 
Tabela 2 - Freqüência dos aspectos envolvidos na definição da condição de ser judeu

\begin{tabular}{|c|c|c|c|c|c|c|c|c|c|c|c|}
\hline \multirow{2}{*}{ categorias: aspectos } & \multicolumn{8}{|c|}{ grupos } & \multicolumn{3}{|c|}{ somatórios } \\
\hline & $\mathrm{a}$ & $\mathrm{b}$ & $\mathrm{c}$ & $\mathrm{d}$ & $\mathrm{e}$ & $\mathrm{f}$ & $\mathrm{g}$ & $\mathrm{h}$ & s1 & $\mathrm{s} 2$ & st \\
\hline religiosos & 2 & 6 & 5 & 2 & 3 & 4 & 5 & 3 & 15 & 15 & 30 \\
\hline culturais & 4 & 5 & 2 & 5 & 2 & 1 & 0 & 3 & 16 & 6 & 22 \\
\hline emocionais & 3 & 4 & 0 & 4 & 1 & 2 & 1 & 5 & 11 & 9 & 20 \\
\hline relativos à descendência & 2 & 2 & 0 & 4 & 5 & 1 & 3 & 3 & 8 & 12 & 20 \\
\hline étnicos & 2 & 3 & 3 & 2 & 0 & 3 & 2 & 3 & 10 & 8 & 18 \\
\hline de identificação com Israel & 1 & 0 & 2 & 2 & 1 & 0 & 2 & 1 & 5 & 4 & 9 \\
\hline etnossociais & 0 & 0 & 0 & 0 & 5 & 0 & 0 & 0 & 0 & 5 & 5 \\
\hline atitudinais & 0 & 0 & 0 & 3 & 0 & 0 & 0 & 0 & 3 & 0 & 3 \\
\hline relativos à conversão & 0 & 0 & 0 & 2 & 1 & 0 & 0 & 0 & 2 & 1 & 3 \\
\hline educacionais & 1 & 0 & 0 & 0 & 0 & 0 & 0 & 1 & 1 & 1 & 2 \\
\hline comunitários & 0 & 0 & 0 & 0 & 0 & 2 & 0 & 0 & 0 & 2 & 2 \\
\hline sociocomunitários & 0 & 0 & 0 & 0 & 0 & 0 & 2 & 0 & 0 & 2 & 2 \\
\hline
\end{tabular}

No que tange ao processo de formação da identidade judaica (Tabela 3), foram ressaltados fatores educacionais (os quais compreendiam, entre outras marcas, estudar em escolas israelitas e receber educação judaica), culturais e religiosos (categorias anteriormente explicadas). Quanto à participação em tal processo (Tabela 4), 87,5\% dos ashkenazim e $85 \%$ dos sefaradim declararam o fazer, sobretudo, por meio de ações educacionais, religiosas e sociocomunitárias (estar em contato com pessoas israelitas, pertencer a movimentos juvenis israelitas, compor grupos de senhoras israelitas, ser membro de clubes, prestando auxílio diverso à comunidade judaica, entre outras respostas).

Tabela 3 - Freqüência dos fatores de formação da identidade judaica

\begin{tabular}{lcccccccc|ccc}
\hline \multicolumn{1}{c}{ categorias: fatores } & \multicolumn{1}{c}{ grupos } & \multicolumn{3}{c}{ somatórios } \\
& $\mathrm{a}$ & $\mathrm{b}$ & $\mathrm{c}$ & $\mathrm{d}$ & $\mathrm{e}$ & $\mathrm{f}$ & $\mathrm{g}$ & $\mathrm{h}$ & $\mathrm{s} 1$ & $\mathrm{~s} 2$ & $\mathrm{st}$ \\
\hline educacionais & 3 & 3 & 6 & 8 & 5 & 8 & 0 & 7 & 20 & 20 & 40 \\
culturais & 4 & 3 & 7 & 6 & 1 & 4 & 0 & 7 & 20 & 12 & 32 \\
religiosos & 4 & 5 & 5 & 2 & 2 & 2 & 5 & 0 & 16 & 9 & 25 \\
emocionais & 3 & 2 & 1 & 2 & 0 & 3 & 1 & 2 & 8 & 6 & 14 \\
familiares & 0 & 6 & 0 & 0 & 2 & 0 & 0 & 5 & 6 & 7 & 13 \\
sociais & 0 & 2 & 0 & 5 & 2 & 0 & 0 & 3 & 7 & 5 & 12 \\
relativos à descendência & 2 & 0 & 1 & 2 & 0 & 0 & 3 & 2 & 5 & 5 & 10 \\
sociocomunitários & 0 & 0 & 3 & 0 & 0 & 0 & 2 & 0 & 3 & 2 & 5 \\
de identificação com Israel & 2 & 0 & 0 & 0 & 0 & 0 & 2 & 0 & 2 & 2 & 4 \\
étnicos & 0 & 0 & 0 & 1 & 0 & 0 & 2 & 0 & 1 & 2 & 3 \\
etnocomunitários & 0 & 0 & 0 & 0 & 0 & 3 & 0 & 0 & 0 & 3 & 3 \\
atitudinais & 1 & 0 & 0 & 0 & 0 & 0 & 0 & 2 & 1 & 2 & 3 \\
de segurança etnonacional & 0 & 0 & 0 & 0 & 1 & 1 & 0 & 0 & 0 & 2 & 2 \\
de conversão & 0 & 0 & 0 & 2 & 0 & 0 & 0 & 0 & 2 & 0 & 2 \\
\hline
\end{tabular}


Tabela 4 - Freqüência dos aspectos envolvidos na participação do sujeito no processo de formação da identidade judaica

\begin{tabular}{|c|c|c|c|c|c|c|c|c|c|c|c|c|}
\hline \multirow{2}{*}{\multicolumn{2}{|c|}{ categorias }} & \multicolumn{8}{|c|}{ grupos } & \multicolumn{3}{|c|}{ somatórios } \\
\hline & & $\mathrm{a}$ & $\mathrm{b}$ & $\mathrm{c}$ & $\mathrm{d}$ & $\mathrm{e}$ & $\mathrm{f}$ & $\mathrm{g}$ & $\mathrm{h}$ & s1 & s2 & st \\
\hline \multicolumn{2}{|r|}{$\operatorname{sim}$} & 6 & 9 & 10 & 10 & 9 & 6 & 9 & 10 & 35 & 34 & 69 \\
\hline \multirow{10}{*}{$\operatorname{sim}$} & educacionais & 2 & 4 & 4 & 6 & 5 & 1 & 4 & 5 & 16 & 15 & 31 \\
\hline & religiosos & 2 & 5 & 5 & 2 & 4 & 3 & 4 & 3 & 14 & 14 & 28 \\
\hline & sociocomunitários & 0 & 7 & 0 & 7 & 0 & 3 & 0 & 4 & 14 & 7 & 21 \\
\hline & culturais & 3 & 0 & 4 & 6 & 0 & 2 & 5 & 0 & 13 & 7 & 20 \\
\hline & históricos e culturais & 0 & 0 & 0 & 0 & 0 & 0 & 0 & 8 & 0 & 8 & 8 \\
\hline & sociais & 2 & 0 & 1 & 0 & 2 & 0 & 2 & 0 & 3 & 4 & 7 \\
\hline & emocionais & 0 & 0 & 0 & 0 & 0 & 0 & 2 & 2 & 0 & 4 & 4 \\
\hline & racionais e emocionais & 0 & 0 & 0 & 2 & 0 & 0 & 0 & 0 & 2 & 0 & 2 \\
\hline & étnicos & 0 & 0 & 0 & 1 & 0 & 0 & 0 & 0 & 1 & 0 & 1 \\
\hline & comunitário-sionistas & 1 & 0 & 0 & 0 & 0 & 0 & 0 & 0 & 1 & 0 & 1 \\
\hline \multicolumn{2}{|r|}{ não } & 3 & 1 & 0 & 0 & 1 & 4 & 1 & 0 & 4 & 6 & 10 \\
\hline \multicolumn{2}{|r|}{ não responderam } & 1 & 0 & 0 & 0 & 0 & 0 & 0 & 0 & 1 & 0 & 1 \\
\hline
\end{tabular}

Quanto à manutenção da identidade ora analisada (Tabela 5), foi concedido destaque a fatores culturais, religiosos, sociais (estar em contato com pessoas israelitas, entre outros pontos) e emocionais. Entretanto, enquanto ashkenazim indicaram a maior importância de aspectos culturais e sociais, sefaradim apontaram para a participação de fatores emocionais e vincularam, ao aspecto social, o compromisso comunitário (prestar diversas formas de auxílio a membros da comunidade israelita).

Tabela 5 - Freqüência dos fatores de manutenção da identidade judaica

\begin{tabular}{|c|c|c|c|c|c|c|c|c|c|c|c|}
\hline \multirow{2}{*}{ categorias: fatores } & \multicolumn{8}{|c|}{ grupos } & \multicolumn{3}{|c|}{ somatórios } \\
\hline & $\mathrm{a}$ & $\mathrm{b}$ & $\mathrm{c}$ & $\mathrm{d}$ & $\mathrm{e}$ & $\mathrm{f}$ & $\mathrm{g}$ & $\mathrm{h}$ & s1 & $\mathrm{s} 2$ & st \\
\hline culturais & 3 & 3 & 6 & 7 & 2 & 1 & 0 & 5 & 19 & 8 & 27 \\
\hline religiosos & 3 & 3 & 4 & 2 & 1 & 3 & 2 & 3 & 12 & 9 & 21 \\
\hline sociais & 2 & 8 & 0 & 3 & 0 & 0 & 0 & 5 & 13 & 5 & 18 \\
\hline emocionais & 1 & 0 & 3 & 3 & 1 & 5 & 2 & 3 & 7 & 11 & 18 \\
\hline sociocomunitários & 0 & 0 & 0 & 0 & 4 & 5 & 6 & 0 & 0 & 15 & 15 \\
\hline educacionais & 0 & 5 & 1 & 1 & 1 & 2 & 2 & 2 & 7 & 7 & 14 \\
\hline familiares & 0 & 0 & 0 & 4 & 0 & 4 & 0 & 0 & 4 & 4 & 8 \\
\hline comunitários & 0 & 0 & 5 & 0 & 0 & 0 & 0 & 0 & 5 & 0 & 5 \\
\hline atitudinais & 0 & 0 & 0 & 0 & 1 & 1 & 0 & 3 & 0 & 5 & 5 \\
\hline relativos à descendência & 1 & 0 & 0 & 0 & 0 & 0 & 2 & 0 & 1 & 2 & 3 \\
\hline de identificação com Israel & 1 & 0 & 0 & 1 & 0 & 0 & 0 & 0 & 2 & 0 & 2 \\
\hline étnicos & 0 & 0 & 1 & 0 & 0 & 1 & 0 & 0 & 1 & 1 & 2 \\
\hline etnonacionais & 0 & 0 & 0 & 0 & 0 & 1 & 0 & 0 & 0 & 1 & 1 \\
\hline
\end{tabular}

Quanto à colaboração dos participantes no processo em questão (Tabela 6), 90\% dos integrantes de ambos os grupos afirmaram realizá-la, sobretudo, através de aspectos educacionais, culturais e sociocomunitários.
Enquanto ashkenazim concederam relevância, principalmente, ao primeiro e último fator, sefaradim o fizeram no que tange aos dois primeiros itens. 
Tabela 6 - Freqüência dos aspectos envolvidos na participação do sujeito no processo de manutenção da identidade judaica

\begin{tabular}{|c|c|c|c|c|c|c|c|c|c|c|c|c|}
\hline \multirow{2}{*}{\multicolumn{2}{|c|}{ categorias }} & \multicolumn{8}{|c|}{ grupos } & \multicolumn{3}{|c|}{ somatórios } \\
\hline & & $\mathrm{a}$ & $\mathrm{b}$ & $\mathrm{c}$ & $\mathrm{d}$ & e & $\mathrm{f}$ & $g$ & $\mathrm{~h}$ & s1 & s2 & st \\
\hline \multicolumn{2}{|r|}{$\operatorname{sim}$} & 6 & 10 & 10 & 10 & 9 & 8 & 9 & 10 & 36 & 36 & 72 \\
\hline \multirow{12}{*}{$\operatorname{sim}$} & educacionais & 1 & 2 & 6 & 2 & 3 & 3 & 3 & 3 & 11 & 12 & 23 \\
\hline & culturais & 0 & 2 & 4 & 3 & 3 & 1 & 2 & 7 & 9 & 13 & 22 \\
\hline & sociocomunitários & 0 & 5 & 0 & 7 & 0 & 3 & 5 & 0 & 12 & 8 & 20 \\
\hline & religiosos & 1 & 2 & 2 & 2 & 2 & 0 & 0 & 4 & 7 & 6 & 13 \\
\hline & históricos e culturais & 0 & 0 & 0 & 9 & 0 & 0 & 0 & 0 & 9 & 0 & 9 \\
\hline & emocionais & 0 & 0 & 0 & 1 & 0 & 1 & 3 & 3 & 1 & 7 & 8 \\
\hline & sociais & 0 & 0 & 0 & 0 & 3 & 0 & 0 & 2 & 0 & 5 & 5 \\
\hline & comunitários & 1 & 0 & 3 & 0 & 0 & 0 & 0 & 0 & 4 & 0 & 4 \\
\hline & de identificação com Israel & 0 & 0 & 0 & 1 & 0 & 1 & 0 & 0 & 1 & 1 & 2 \\
\hline & etnopolíticos & 0 & 0 & 0 & 2 & 0 & 0 & 0 & 0 & 2 & 0 & 2 \\
\hline & atitudinais & 0 & 0 & 0 & 0 & 0 & 1 & 0 & 1 & 0 & 2 & 2 \\
\hline & étnicos & 0 & 1 & 0 & 0 & 0 & 0 & 0 & 0 & 1 & 0 & 1 \\
\hline \multicolumn{2}{|r|}{ não } & 1 & 0 & 0 & 0 & 1 & 2 & 0 & 0 & 1 & 3 & 4 \\
\hline \multicolumn{2}{|r|}{ não responderam } & 2 & 0 & 0 & 0 & 0 & 0 & 0 & 0 & 2 & 0 & 2 \\
\hline \multicolumn{2}{|r|}{ respostas não consideradas } & 1 & 0 & 0 & 0 & 0 & 0 & 1 & 0 & 1 & 1 & 2 \\
\hline
\end{tabular}

No que se refere a mudanças na expressão do Judaísmo (Tabela 7), aproximadamente $92,5 \%$ dos ashkenazim e $85 \%$ dos sefaradim responderam perceber modificações, principalmente, no âmbito religioso. Com relação aos fatores que contribuíram para tais mudanças (Tabela 8), os grupos apontaram para condições referentes ao desenvolvimento mundial (progresso, novas condições de vida em sociedade, exigências do mundo moderno, entre outras respostas).

Tabela 7 - Freqüência das mudanças nas formas de expressão do judaísmo

\begin{tabular}{|c|c|c|c|c|c|c|c|c|c|c|c|c|}
\hline \multirow{2}{*}{\multicolumn{2}{|c|}{ categorias }} & \multicolumn{8}{|c|}{ grupos } & \multicolumn{3}{|c|}{ somatórios } \\
\hline & & $\mathrm{a}$ & $\mathrm{b}$ & $\mathrm{c}$ & $\mathrm{d}$ & $\mathrm{e}$ & $\mathrm{f}$ & $g$ & $\mathrm{~h}$ & s1 & s2 & st \\
\hline & $\operatorname{sim}$ & 10 & 8 & 10 & 9 & 7 & 9 & 8 & 10 & 37 & 34 & 71 \\
\hline \multirow{10}{*}{$\operatorname{sim}$} & religiosas & 3 & 4 & 8 & 3 & 2 & 6 & 4 & 6 & 18 & 18 & 36 \\
\hline & de desenvolvimento mundial & 5 & 2 & 0 & 5 & 0 & 0 & 1 & 0 & 12 & 1 & 13 \\
\hline & étnicas & 0 & 1 & 2 & 2 & 5 & 0 & 0 & 0 & 5 & 5 & 10 \\
\hline & sociais & 2 & 0 & 0 & 0 & 0 & 1 & 0 & 5 & 2 & 6 & 8 \\
\hline & de segurança etnonacional & 1 & 0 & 0 & 0 & 2 & 0 & 0 & 1 & 1 & 3 & 4 \\
\hline & racionais & 0 & 0 & 1 & 0 & 1 & 1 & 0 & 1 & 1 & 3 & 4 \\
\hline & socioculturais & 0 & 0 & 0 & 0 & 0 & 0 & 3 & 0 & 0 & 3 & 3 \\
\hline & emocionais & 0 & 0 & 0 & 0 & 0 & 1 & 0 & 1 & 0 & 2 & 2 \\
\hline & políticas & 0 & 0 & 0 & 1 & 0 & 0 & 0 & 0 & 1 & 0 & 1 \\
\hline & relativas à aparência & 0 & 0 & 0 & 0 & 0 & 1 & 0 & 0 & 0 & 1 & 1 \\
\hline \multicolumn{2}{|r|}{ não } & 0 & 1 & 0 & 1 & 2 & 1 & 1 & 0 & 2 & 4 & 6 \\
\hline \multicolumn{2}{|r|}{ não responderam } & 0 & 0 & 0 & 0 & 1 & 0 & 1 & 0 & 0 & 2 & 2 \\
\hline \multicolumn{2}{|r|}{ respostas não consideradas } & 0 & 1 & 0 & 0 & 0 & 0 & 0 & 0 & 1 & 0 & 1 \\
\hline
\end{tabular}


Quanto ao estabelecimento de relações significativas de amizade e de amor entre judeus e nãojudeus (oitava pergunta do questionário), cerca de 60\% de participantes ashkenazim e 47,5\% de sefaradim apoiaram tais relacionamentos, enquanto $35 \%$ do primeiro conjunto e $30 \%$ do segundo grupo eram a favor de relações de amizade e contrários às de amor. Quanto a ser contrário ao estabelecimento de relações de amizade e de amor, nenhum participante ashkenazi revelou tal condição e $10 \%$ dos participantes sefaradim se declararam nesta posição. Cabe mencionar que não foi possível considerar as respostas fornecidas por dois participantes ashkenazim e cinco sefaradim.

Tabela 8 - Freqüência dos fatores de mudanças nas formas de expressão do judaísmo

\begin{tabular}{|c|c|c|c|c|c|c|c|c|c|c|c|}
\hline \multirow{2}{*}{ categorias: fatores } & \multicolumn{8}{|c|}{ grupos } & \multicolumn{3}{|c|}{ somatórios } \\
\hline & $\mathrm{a}$ & $\mathrm{b}$ & $\mathrm{c}$ & $\mathrm{d}$ & $\mathrm{e}$ & $\mathrm{f}$ & $\mathrm{g}$ & $\mathrm{h}$ & s1 & $\mathrm{s} 2$ & st \\
\hline de desenvolvimento mundial & 2 & 2 & 3 & 6 & 0 & 6 & 4 & 3 & 13 & 13 & 26 \\
\hline étnicos & 2 & 4 & 1 & 2 & 3 & 0 & 0 & 2 & 9 & 5 & 14 \\
\hline de segurança etnonacional & 1 & 0 & 2 & 2 & 1 & 0 & 1 & 2 & 5 & 4 & 9 \\
\hline sociais & 2 & 0 & 1 & 1 & 1 & 1 & 0 & 1 & 4 & 3 & 7 \\
\hline religiosos & 2 & 4 & 0 & 0 & 0 & 0 & 0 & 0 & 6 & 0 & 6 \\
\hline educacionais & 0 & 0 & 1 & 0 & 1 & 0 & 2 & 0 & 1 & 3 & 4 \\
\hline culturais & 0 & 0 & 0 & 0 & 0 & 0 & 0 & 3 & 0 & 3 & 3 \\
\hline emocionais & 1 & 0 & 1 & 0 & 0 & 0 & 0 & 1 & 2 & 1 & 3 \\
\hline racionais & 0 & 1 & 0 & 2 & 0 & 0 & 0 & 0 & 3 & 0 & 3 \\
\hline socioculturais & 0 & 0 & 0 & 0 & 0 & 0 & 2 & 0 & 0 & 2 & 2 \\
\hline relativos à assimilação & 0 & 0 & 2 & 0 & 0 & 0 & 0 & 0 & 2 & 0 & 2 \\
\hline mudança no papel da mulher & 0 & 0 & 0 & 2 & 0 & 0 & 0 & 0 & 2 & 0 & 2 \\
\hline perda de segurança nacional & 0 & 0 & 1 & 0 & 0 & 0 & 0 & 0 & 1 & 0 & 1 \\
\hline aceitação do casamento misto & 0 & 0 & 0 & 1 & 0 & 0 & 0 & 0 & 1 & 0 & 1 \\
\hline racionais e emocionais & 0 & 0 & 0 & 0 & 0 & 1 & 0 & 0 & 0 & 1 & 1 \\
\hline
\end{tabular}

Com referência aos acordos de paz desenvolvidos entre Israel e países vizinhos (nona pergunta do questionário), 80\% dos ashkeenazim e 75\% dos sefaradim se mostraram favoráveis aos mesmos. Ainda no que tange àqueles, um participante afirmou ser favorável a alguns acordos e desfavorável a outros, dois participantes apenas responderam que desconfiavam dos acordos, e cinco pessoas não responderam adequadamente à questão. Quanto aos sefaradim, dez participantes não declararam de forma explícita se eram favoráveis ou não aos acordos, de modo que estas respostas não foram consideradas.

\section{Discussão dos Resultados}

Tomando por base os dados empíricos reunidos, observou-se que a configuração da identidade judaica compreende aspectos religiosos, culturais, educacionais, sociocomunitários, relativos à descendência e à conversão religiosa, de identificação com Israel, emocionais, racionais, atitudinais, entre outros fatores. Acredita-se que, reconhecendo-se as especificidades de cada fator, possam ser estabelecidas relações entre os mesmos. Entretanto, antes de serem propostas tais articulações, faz-se necessário comentar que a apresentação de respostas comuns, por parte de ashkenazim e sefaradim, parece apontar para a condição de igualdade que há entre estas pessoas, isto é, a de pertencer a uma categoria primeira e maior - ser israelita.

Deste modo, aspectos religiosos e culturais foram associados, já que os primeiros reúnem não só leis divinas que esclarecem como israelitas devem viver, procedimentos a serem seguidos, rezas a serem feitas, mas também histórias que explicam o significado de mandamentos, festividades e lendas, histórias estas que contribuem para transmissão e sustentação de fatores culturais. Estes, por sua vez, envolvem o cumprimento de práticas religiosas, sendo necessário apenas ressaltar que existem diferentes formas de segui-las, isto é, formas ortodoxas e não-ortodoxas.

Cabe salientar que a articulação ora comentada vem ao encontro de consideração anteriormente feita, 
isto é, que a Torá compreende, através de recursos descritivos, normativos e avaliativos, toda a legislação civil e religiosa que deve perpassar a existência dos israelitas. Além da Torá, em sua forma escrita, houve a transmissão da mesma de forma oral, transmissão que, ao ser transcrita, constituiu a Mishná. A Mishná e os comentários desenvolvidos a seu respeito - a Guemaráformam o Talmud. Este, por sua vez, reúne considerações que envolvem dois tipos de elementos: a Halaká e a Agadá. Enquanto a primeira se refere a leis religiosas que devem ser obedecidas, a segunda revela, por meio de narrativas que descrevem histórias e lendas, aspectos éticos e teológicos. Estes breves comentários, acerca de algumas obras existentes no Judaísmo, parecem apontar para a articulação entre as esferas religiosa e cultural.

Aspectos educacionais foram vinculados aos acima mencionados, uma vez que envolvem modos formais de obtenção e transmissão de conhecimentos judaicos, como escolas, sinagogas e bibliotecas, e modos informais. É preciso ressaltar que a sinagoga exerce função educacional, na medida em que a religião judaica defende a obediência aos mandamentos divinos, porém uma obediência consciente e esclarecida, a qual seja marcada pelo estudo da palavra de Deus. Com relação aos modos informais, há transmissão de conhecimentos pela prática de tradições familiares, pelo contato com pessoas israelitas, envolvimento em entidades assistenciais comunitárias, entre outras condições.

Acredita-se que aspectos sociais estejam vinculados às dimensões citadas, pois o contato com outros indivíduos ou pequenos grupos israelitas ocorre em âmbito religioso, cultural e educacional. Quanto aos aspectos comunitários, percebe-se o compromisso em se prestar assistência à comunidade judaica, compromisso este assumido por diversas instituições, formais ou não. Fatores étnicos também podem ser associados aos aspectos acima mencionados, já que revelam a condição do indivíduo de perceber que pertence a um grupo que se diferencia dos demais pela história, por crenças religiosas, valores, tradições, entre outras características. Com base nas respostas fornecidas pelos participantes, constatouse que a dimensão étnica se fez presente na formação da identidade em questão, porém de modo comedido e consciente, não envolvendo seja uma postura etnocêntrica, seja um movimento de excessiva aculturação.

Ainda no que tange ao contato entre israelitas e outros grupos, parece que fatores de identificação com Israel também participam do delineamento em foco, fatores que expressam compromissos emocionais, racionais e atitudinais para com Israel, compromissos que podem ocorrer em âmbito religioso, cultural, político, entre outros. Acredita-se que a existência de israelitas em diversos locais do mundo, e os inúmeros episódios de perseguição sofridos, contribuam para a presença de aspectos relativos à identificação com Israel, presença revelada nos processos de formação e manutenção da identidade judaica.

Por fim, cabe mencionar que fatores relativos à descendência e à conversão foram articulados aos aspectos religiosos e étnicos, pois representam as duas formas possíveis do indivíduo ser considerado judeu. Foram assinalados ainda aspectos emocionais, racionais e atitudinais no delineamento em foco. Enquanto aqueles parecem revelar a importância de se considerar não apenas a inclusão do indivíduo em um determinado conjunto social, mas, sobretudo, o sentimento atribuído a tal pertencimento, aspectos racionais podem ser relacionados ao papel desempenhado por crenças psicossociológicas na configuração de identidades psicossociais, crenças que interferem nas condutas apresentadas, componentes que compõem atitudes.

Quanto ao processo de modificação da identidade judaica, acredita-se que as respostas fornecidas, relativas às transformações na expressão religiosa, apontem para diferentes formas de exercício desta dimensão, mas não para o abandono da mesma. Isto porque foi conferida relevância aos aspectos religiosos ao longo das respostas referentes à definição, ao processo de formação, à participação na construção, ao processo de manutenção e à colaboração com a sustentação da condição de ser judeu.

Assim, acredita-se que a identidade judaica, mesmo compreendendo contínuos processos de formação, manutenção e possível modificação, apresente contornos comuns e bem delineados. Este caráter comum não significa a rigidez desta configuração, parecendo apenas assinalar que as mudanças ocorridas não consistem em drásticas rupturas, mas, sim, em discretas modificações quanto ao grau de expressão dos referidos aspectos. Isto porque, apesar do não-oferecimento, por parte do Judaísmo, de um significativo espaço para a instauração de modificações relativas a condições temporais e/ou socioculturais existentes, parece que todos nós, judeus ou não, estamos sujeitos a condicionamentos históricos que interferem em nossa visão de mundo e na interpretação que concedemos a nós mesmos.

\section{Referências}

Asheri, M. (1995). O judaísmo vivo: as tradições e as leis dos judeus praticantes. Rio de Janeiro, RJ: Imago.

Augoustinos, M. \& Walker, I. (1995). Social cognition - an integrated introduction. London, Thousand OaksNew Delhi: SAGE.

Brewer, M. \& Gardner, W. (1996). Who is this "we"? Levels of collective identity and self representations. Journal of Personality and Social Psychology, 71(1), 83-93. 
Corrêa Neto, F. (1987). Os judeus: povo ou religião? Rio de Janeiro, RJ: Erca.

Dahrendorf, R. (1969). Homo sociologicus. Rio de Janeiro, RJ: Tempo Brasileiro.

Deaux, K., Reid, A., Mizrahi, K. \& Ethier, K. (1995). Parameters of social identity. Journal of Personality and Social Psychology, 68(2), 280-291.

Drever, J. (1965). A dictionary of Psychology. London: Penguin Books.

Epelboim, S. (1997). Identidade judaica: formação, manutenção e possivel modificação. (Dissertação de Mestrado). Rio de Janeiro: Universidade Federal do Rio de Janeiro - Instituto de Psicologia.

Erikson, E. (1968). Identity, psychosocial. Em D. L. Sills (Ed.). International encyclopedia of the social sciences. New York: Macmillan.

Erikson, E. (1976). Infância e sociedade. Rio de Janeiro, RJ: Zahar.

Erikson, E. (1987). Identidade, juventude e crise. Rio de Janeiro, RJ: Ed. Guanabara.

Hollanda, A. B. (1967). Pequeno dicionário brasileiro da língua portuguesa. Rio de Janeiro, RJ: Ed. Civilização Brasileira.

Krüger, H. (1986). Introdução a Psicologia Social. São Paulo, SP: EPU.

Krüger, H. (1995a). Psicologia das crenças: perspectivas teóricas. (Tese de Concurso para Professor Titular). Rio de Janeiro: Universidade do Estado do Rio de
Janeiro - Instituto de Psicologia - Departamento de Psicologia Social e Institucional.

Krüger, H. (1995b). Identidade étnica, identidade transcultural e transnacionalismo. Monografias Psicológicas, 10, 21-43.

Krüger, H. (1995c). Notas sobre a identidade teutobrasileira. Monografias Psicológicas, 10, 7-20.

Lillenthal, A. (1997). O povo de Deus, quem é? Em H. Lewin (Org.). Judaísmo: memória e identidade. (pp. 155164). Rio de Janeiro, RJ: Ed. UERJ.

Oyserman, D. (1993). The lens of personhood viewing the self and others in a multicultural society. Journal of Personality and Social Psychology, 65(5), 993-1009.

Pereira, O. G. \& Jesuíno, J. C. (1985). Psicologia Social do Desenvolvimento - socialização e saúde mental. Lisboa: Livros Horizonte.

Reid, A. \& Deaux, K. (1996). Relationship between social and personal identities: Segregation or integration? Journal of Personality and Social Psychology, 71(6), 1084-1091.

Rorty, A. O. \& Wong, D. (1990). Aspects of identity and agency. Em O. Flanagan \& A. O. Rorty (Org.). Identity, character and morality. (pp. 19-36). Cambridge, Massachusetts: Mit Press.

Recebido em março de 2004 Reformulado em maio de 2004 Aprovado em junho de 2004

Sobre a autora:

Solange Epelboim é psicóloga, mestre e doutoranda em Psicologia Social, na Universidade do Estado do Rio de Janeiro, e professora nas Faculdades Integradas Maria Thereza, Universidade Católica de Petrópolis e na Universidade Estácio de Sá. 
